\title{
Poverty and Program Participation among Immigrant Children
}

\section{Citation}

Borjas, George. 2011. Poverty and Program Participation among Immigrant Children. The Future of Children 21(1): 247-266.

\section{Published Version}

http://futureofchildren.org/futureofchildren/publications/docs/21_01_11.pdf

\section{Permanent link}

http://nrs.harvard.edu/urn-3:HUL.InstRepos:8052147

\section{Terms of Use}

This article was downloaded from Harvard University's DASH repository, and is made available under the terms and conditions applicable to Other Posted Material, as set forth at http:// nrs.harvard.edu/urn-3:HUL.InstRepos:dash.current.terms-of-use\#LAA

\section{Share Your Story}

The Harvard community has made this article openly available.

Please share how this access benefits you. Submit a story.

\section{Accessibility}




\title{
Poverty and Program Participation among Immigrant Children
}

\author{
George J. Borjas
}

\section{Summary}

Researchers have long known that poverty in childhood is linked with a range of negative adult socioeconomic outcomes, from lower educational achievement and behavioral problems to lower earnings in the labor market. But few researchers have explored whether exposure to a disadvantaged background affects immigrant children and native children differently. George Borjas uses Current Population Survey (CPS) data on two specific indicators of poverty- the poverty rate and the rate of participation in public assistance programs - to begin answering that question.

He finds that immigrant children have significantly higher rates both of poverty and of program participation than do native children. Nearly half of immigrant children are being raised in households that receive some type of public assistance, compared with roughly one-third of native children. Although the shares of immigrant and native children living in poverty are lower, the rate for immigrant children is nonetheless about 15 percentage points higher than that for native children-about the same as the gap in public assistance. Poverty and program participation rates among different groups of immigrant children also vary widely, depending in part on place of birth (foreign- or U.S.-born), parents (immigrant or native), and national origin.

According to the CPS data, these native-immigrant differences persist into young adulthood. In particular, the program participation and poverty status of immigrant children is strongly correlated with their program participation and poverty status when they become young adults. But it is not possible, says Borjas, to tell whether the link results from a set of permanent factors associated with specific individuals or groups that tends to lead to "good" or "bad" outcomes systematically over time or from exposure during childhood to adverse socioeconomic outcomes, such as poverty or welfare dependency. Future research must explore the causal impact of childhood poverty on immigrant adult outcomes and why it might differ between immigrant and native families. Developing successful policies to address problems caused by the intergenerational breeding of poverty and program participation in the immigrant population depends on understanding this causal mechanism.

www.futureofchildren.org

George J. Borjas is the Robert W. Scrivner Professor of Economics and Social Policy at the John F. Kennedy School of Government at Harvard University and a research associate of the National Bureau of Economic Research. 


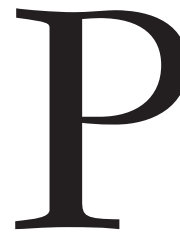
overty in childhood has long been recognized as a determinant of a wide range of negative socioeconomic outcomes from lower educational achievement and behavioral problems to lower earnings in the labor market. But few researchers have explored whether childhood poverty affects native and immigrant children differently. In this article, I use data on two specific indicators of poverty-the poverty rate and the rate of participation in public assistance programs - to begin answering that question. The data suggest that the program participation rate is significantly higher for immigrant children than for native children. Nearly half of immigrant children-a remarkably large fraction - are being raised in households that receive some type of public assistance, compared with roughly one-third of native children. Although the shares of immigrant and native children living in poverty are lower, the rate for immigrant children is nonetheless about 15 percentage points higher than that for native childrenthe same as the gap for public assistance. The evidence also suggests that these nativeimmigrant differences persist into young adulthood. In particular, the program participation and poverty status of immigrant children is strongly correlated with their program participation and poverty status a decade later when they become young adults. It is not possible, however, to tell whether this link results from a long-term persistence in socioeconomic outcomes or is a causal effect of the adverse exposure that occurs during the childhood years.

The exact implications of these findings are not yet completely understood, but they have potentially significant policy and social ramifications. Over the past four decades, the foreign-born share of the U.S. population grew from 4.7 percent to 12.9 percent - an increase that presages rapid growth in the next few decades in the number of children born in the United States with at least one foreign-born parent. ${ }^{1}$ In an important sense, the close link between the skills of parents and those of their children suggests that current immigration policy has already determined the skill endowment of the workforce for the next two or three generations. Therefore, understanding both the impact of immigration and the likely future trends in socioeconomic conditions for a large and growing segment of our population requires a careful study of "the coming of age" of immigrant children.

\section{Filling a Gap in the Research}

Much of the immigration literature in the social sciences, however, focuses on trends in the relative skills of immigrants or determining how immigration alters the economic opportunities available to the native-born population. Some immigration studies examine the social mobility of immigrant households. ${ }^{2}$ The notion that social, cultural, and economic differences between immigrants and natives fade over the course of a few generations is the essence of the meltingpot hypothesis. Over time, the children and grandchildren of immigrants tend to move out of ethnic enclaves, discard their social and cultural background, and become indistinguishable from the native population. Estimates of the rate of intergenerational convergence across the many national origin groups suggests that although the melting pot operates, the economic differences observed among the various groups may not dissolve for at least two or three generations.

Although this long-run perspective is insightful, the examination of the well-being of immigrant children changes the focus of 
analysis from the rate of intergenerational social mobility to a host of short-run concerns that can increase our understanding of the experiences of immigrant households. For example, how does the background of immigrant families influence the socioeconomic outcomes for immigrant children? Do these background characteristics explain a significant part of the observed differences between native and immigrant children and among the various national origin groups within the immigrant population?

One such background characteristic is poverty. A large literature has isolated the incidence and timing of poverty during childhood as a crucial determinant of a wide array of socioeconomic outcomes both in the short and long run. ${ }^{3}$ For example, evidence shows that growing up in a poor household can adversely affect a child's academic achievement. Similarly, poverty correlates strongly and negatively to the probability that a child graduates from high school. Some studies attempting to uncover the root causes of these adverse outcomes have found evidence suggesting that poverty affects social and emotional development, with children raised in poverty having a higher incidence of behavioral problems that are likely to mar the school experience and lead to poorer academic outcomes. ${ }^{4}$

That the negative impact of childhood poverty extends well beyond academic achievement is also well known. Poor children, for instance, experience less favorable health outcomes, including a higher propensity for low birth weight and a higher mortality rate in the first month of life. ${ }^{5}$ The health-related consequences continue into adolescence. Poorer children have a greater risk of experiencing accidents and injuries and a higher probability of teen childbearing.
Finally, the literature shows that the impact of childhood poverty persists into adulthood. ${ }^{6}$ A poverty spell during childhood increases the probability that the adult will have lower earnings and greatly increases the probability that the adult will also experience a poverty spell. In other words, childhood poverty breeds adult poverty.

Much of the literature examining the incidence of childhood poverty and the link between childhood poverty and other socioeconomic outcomes ignores the potential differences that may exist between immigrant and native children. The frequency and the length of poverty spells likely differ between immigrant and native children (as well as among the national origin groups that make up the immigrant population). Moreover, child poverty could potentially have different consequences for immigrant and native children. Put differently, exposure to a disadvantaged background may imply different things for different groups of children, particularly because the immigrant experience introduces distinct factors that native children avoid (such as a temporary family separation resulting from the vagaries of immigration law).

\section{The Population of Immigrant Children: A Descriptive Analysis}

The U.S. Census Bureau began to collect information on the birthplace of participants and their parents in the Current Population Survey (CPS) in 1994. The Annual Demographic Files of the CPS (also known as the March Supplements) provide detailed information about whether a family's total income is below the poverty threshold and whether the household participated in various types of social assistance programs during the calendar year before the survey. The evidence summarized below for immigrant and native households over the past fifteen years is 
Figure 1. Trends in the Share of Immigrant Children, 1994-2009

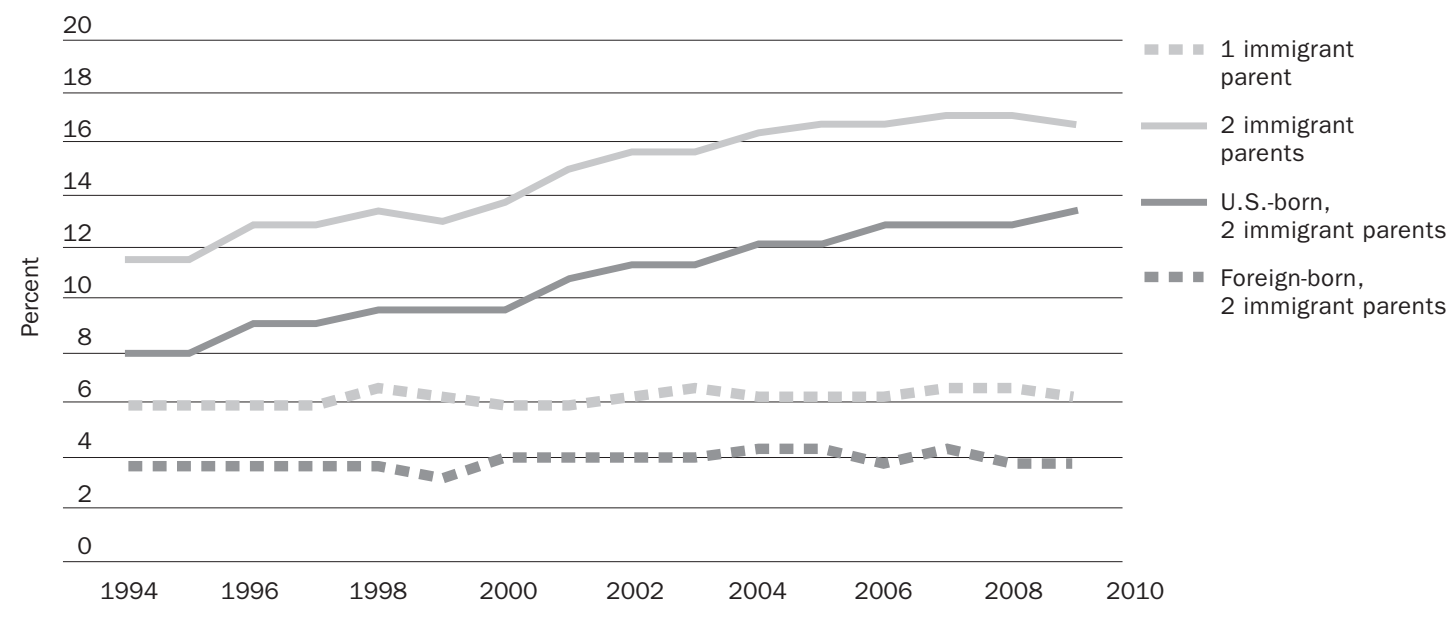

Source: Author's calculations from the 1994-2009 March Current Population Surveys.

Note: The population of children includes all persons aged seventeen or less.

drawn from those data in the 1994-2009 CPS March Supplements. The observed trends during this period reflect the combined impact of the enactment of welfare reform legislation in 1996, the continuation of a high volume of legal and illegal immigration into the United States, and a lengthy economic boom followed abruptly by a deep recession.

A crucial first step is the definition of "immigrant children." The definition used in most of the other articles in this volume defines immigrant children as those who are foreignborn and migrate to the United States with their foreign-born parents and those who are U.S.-born to one or two immigrant (foreignborn) parents. I place immigrant children into three groups: children who have one immigrant parent (here called "mixed parents"); ${ }^{7}$ foreign-born children who have two immigrant parents; and U.S.-born children who have two immigrant parents. The differences in socioeconomic outcomes between these three groups of immigrant children are important, so they will be differentiated throughout the analysis. Finally, the residual group is composed of "native" childrenU.S.-born children whose parents also were born in the United States. Figure 1 summarizes the trend since 1994 in the relative size of the various groups of immigrant children aged seventeen or younger, classified according to the birthplace of the parents and of the children. ${ }^{8}$

The fraction of children who have at least one immigrant parent has increased substantially, from 17.5 percent of all children in 1994 to 23.2 percent in 2009 . The fraction of mixedparent children in the population hovered around 6 percent throughout the entire sample period, while the fraction of children with two immigrant parents rose from 11.6 to 16.9 percent. The rate of increase in the share of immigrant children is much higher than the corresponding increase in the share of foreign-born persons in the total population. In 1994, 9.6 percent of the total U.S. population was foreign-born; by 2009 , the foreignborn share had increased to 12.9 percent. 
Figure 2. Trends in the Poverty Rate of Children, 1994-2009

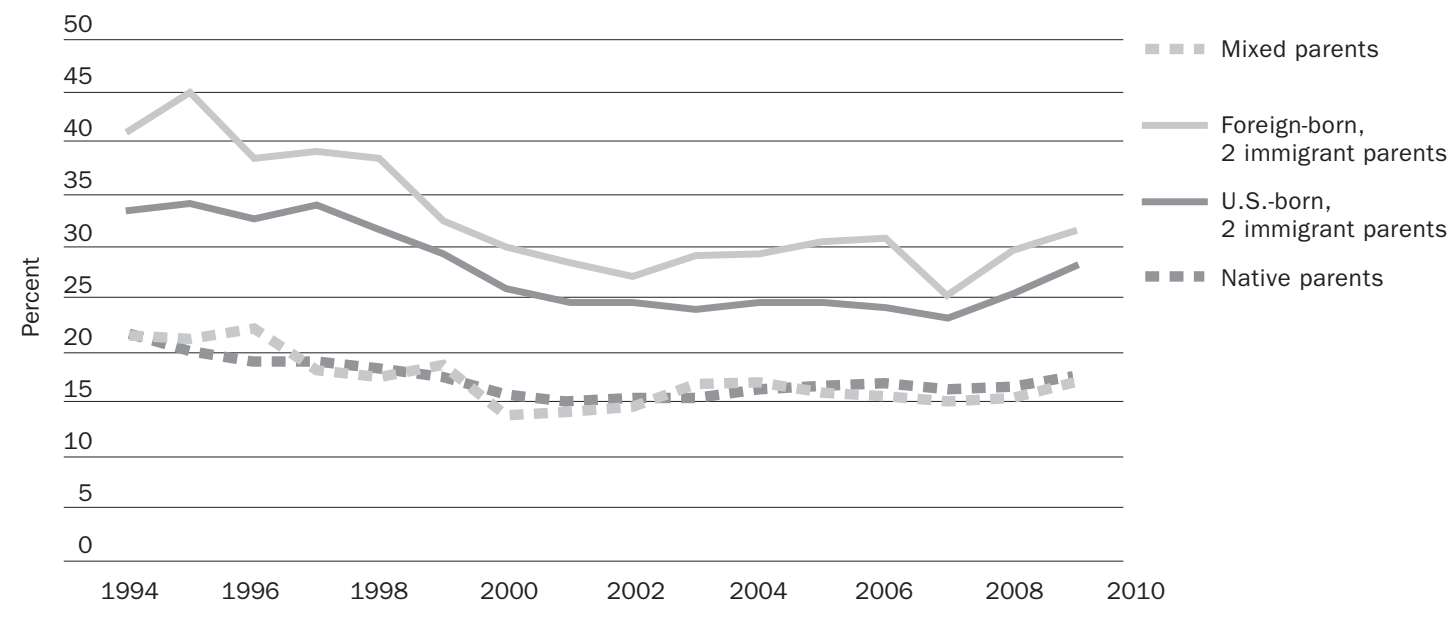

Source: Author's calculations from the 1994-2009 March Current Population Surveys.

Note: The poverty rate gives the fraction of households with incomes below the poverty threshold.

The vast majority of immigrant childrenaround 80 percent-are, in fact, born in the United States. ${ }^{9}$ While the fraction of immigrant children born abroad has remained relatively constant (around 4 percent of all children throughout the period), the fraction of immigrant children born in the United States rose dramatically, from under 12 percent of all children in 1994 to almost 17 percent by 2009 .

\section{Poverty and Program Participation Rates}

The socioeconomic background of the households where immigrant children are raised is likely to have lasting influence on a wide array of outcomes as these children grow up, complete their education, and enter the labor market. As noted, a crucial variable that may have long-term detriments is the likelihood that the immigrant child grows up in a poor household. Although a large literature documents the consequences of childhood poverty on a wide array of socioeconomic outcomes, the existing studies do not typically examine the poverty or public assistance participation rates of immigrant children, much less study the long-term consequences of a disadvantaged childhood in an immigrant household. Researchers and policy makers can thus view this article as a first attempt to document issues related to poverty and program participation among immigrant households in the past decade and to reveal the trends that may become important determinants of future outcomes in this population.

The poverty rate is defined as the fraction of children in a particular group that is being raised in households where family income is below the poverty threshold. Figure 2 illustrates the trends in poverty rates among the various groups of children being examined. Note, for example, that neither the level nor the trend in poverty rates differs much between native and mixed-parent children. In 2009, about 17 percent of children in both of these groups were being raised in households where income fell below the poverty threshold. 
In contrast, the poverty rate of children with two immigrant parents is higher, particularly for immigrant children born abroad. In 2009, the poverty rate of U.S.-born children with two immigrant parents was 28.5 percent, while that for foreign-born children was 31.6 percent. The figure also reveals a noticeable relative decline in the poverty rate of these two groups of children between 1996 and 2000 (which may reflect the economic boom of the late 1990s or be related to the timing of the welfare reform legislation). Finally, the figure shows that the poverty rate of these children has increased rapidly in the past few years, relative to those of children with native or mixed parents, perhaps reflecting the worsening economic conditions after 2007. For instance, between 2007 and 2009 the poverty rate barely rose for native children but increased by around 5 percentage points for U.S.-born children with two immigrant parents and by 6 percentage points for foreignborn children with two immigrant parents.

To what extent do immigrant children live in households that receive public assistance? That question is interesting for two reasons. First, some of this assistance presumably helps to lower the measured poverty rate in immigrant households. ${ }^{10}$ Second, exposure to the public assistance infrastructure during childhood may itself have long-term consequences, some harmful and some beneficial. It may, for example, introduce the seeds of a culture of dependency that may persist into adulthood. Or it may, in some forms, such as Medicaid, serve as a form of human capital investment, leading to healthier and more favorable health and economic outcomes as the children grow up. ${ }^{11}$

To document the extent to which immigrant children are exposed to welfare programs during their childhood, I turn again to the
CPS data, which report whether anyone in the household received cash benefits or food stamps (now known as the Supplemental Nutrition Assistance Program, or SNAP) or was enrolled in the Medicaid program. The summary definition of program participation that I initially use in the analysis indicates whether anyone in the household received assistance from any of these three programs. The top panel of figure 3 illustrates the trend in this measure of the program participation rate during the sample period for the four groups of children in the data: native children, mixed-parent children, U.S.-born children with two immigrant parents, and foreign-born children with two immigrant parents.

Figure 3 reveals a number of interesting results. First, as with the poverty rate, program participation rates differ little between native children and children of mixed parentage. Both the level and trend of participation rates in these groups are remarkably similar during 1994-2009. In contrast, whether they were U.S.-born or foreign-born, children with two immigrant parents live in households that overall have higher rates of program participation. In 2009, the program participation rate was 51.5 percent for the U.S.-born children and 38.6 percent for the foreign-born children. In other words, slightly over half of all U.S.-born children with immigrant parents lived in a household where someone received some type of assistance. In contrast, the participation rate for native or mixed-parent children was around 33 percent.

The data show that foreign-born children have the highest measured poverty rate but that U.S.-born children with immigrant parents have the highest program participation rate. The latter finding is not surprising: it is the citizen children in these households who 
Figure 3. Trends in Program Participation of Children, 1994-2009

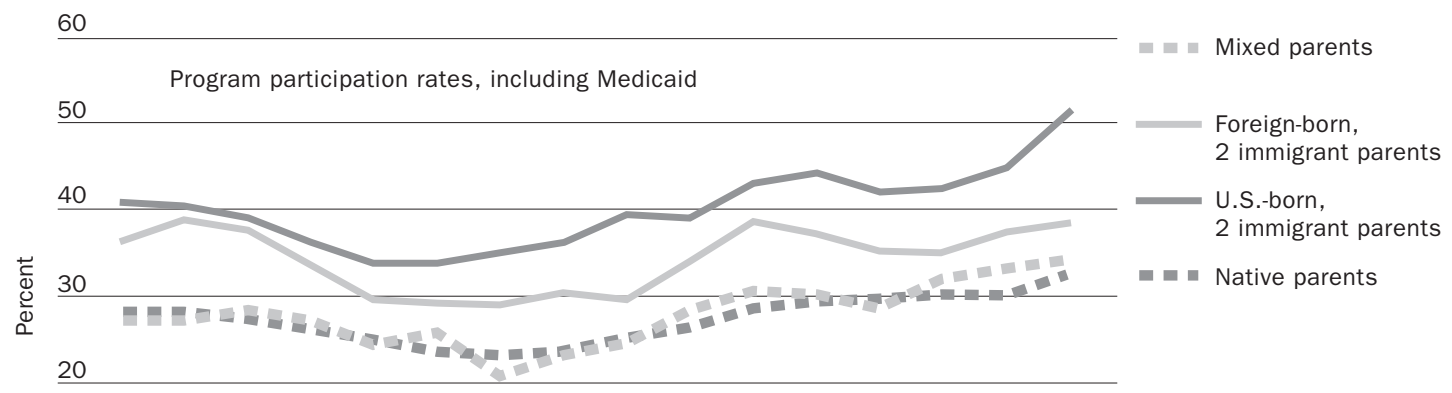

10

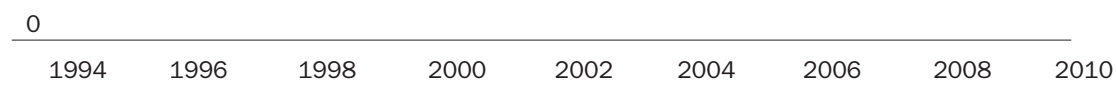

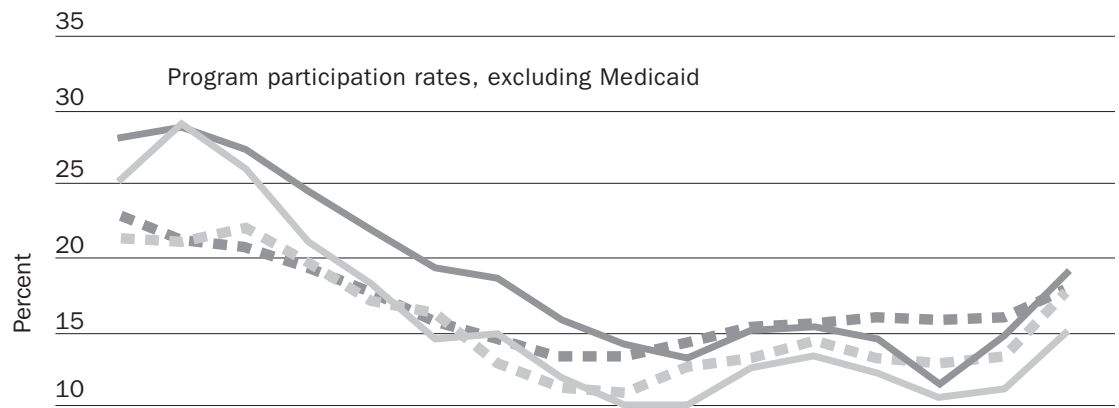

Mixed parents

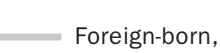

2 immigrant parents

U.S.-born,

2 immigrant parents

5

0

$\begin{array}{lllllllll}1994 & 1996 & 1998 & 2000 & 2002 & 2004 & 2006 & 2008 & 2010\end{array}$

Source: Author's calculations from the 1994-2009 March Current Population Surveys.

Note: The program participation rate gives the fraction of children living in households that received cash assistance, SNAP benefits, or Medicaid (in the top panel), or cash assistance and SNAP benefits (in the bottom panel).

qualify for various types of public assistance. But the differential outcomes in program participation and poverty between these two groups of children hint at the possibility that some of the public assistance restrictions imposed on children born abroad have important consequences on the socioeconomic status of the households in which they grow up.

The top panel of figure 3 reveals another interesting difference in the program participation trends, this one between children with two immigrant parents and other children. Even though children with two immigrant parents have a higher participation rate throughout the entire fifteenyear period, that rate declines dramatically immediately after enactment of welfare reform legislation in 1996 (and this decline is noticeably steeper for the foreign-born children). The Personal Responsibility and Work Opportunity Reconciliation Act, or 
Figure 4. Differences in Poverty Rates by National Origin of Immigrant Children, 1994-2009

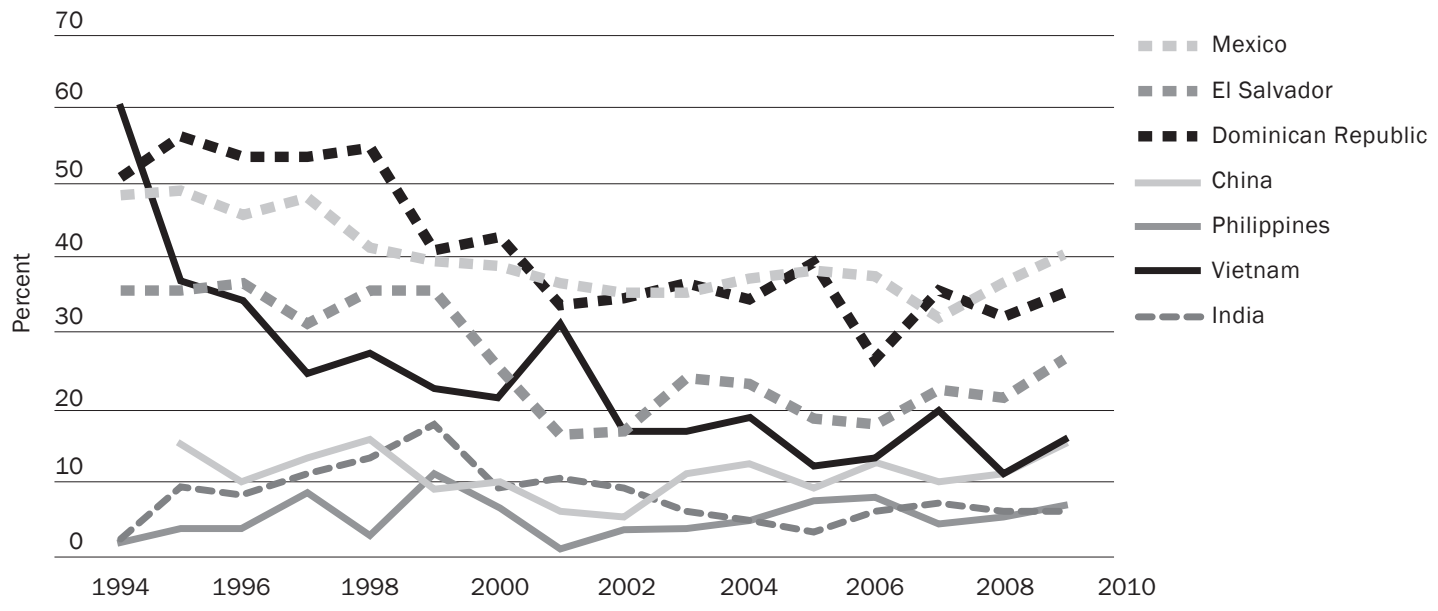

Source: Author's calculations from the 1994-2009 March Current Population Surveys.

Note: The population of immigrant children includes all persons aged seventeen or less whose parents were born outside the United States or its possessions.

PRWORA, led to a relatively steeper drop in immigrant participation in welfare programs, perhaps because of the "chilling effect" of several provisions in the statute that restricted noncitizen eligibility for these programs. ${ }^{12}$ The trends illustrated in the figure suggest the presence of this chilling effect in the families of children with two immigrant parents, particularly in the families of foreign-born children (children who are not U.S. citizens and therefore do not qualify for many types of assistance in the post-PRWORA period). Note further the growing divergence in recent years between U.S.-born children with two immigrant parents, who have experienced a very rapid rise in participation rates, and all other groups of children. In fact, the figure clearly indicates that this group of children has the fastestrising rate of program participation among the various groups in the analysis.

Many of the trends revealed in the top panel of figure 3 are driven by the inclusion of Medicaid in the definition of whether the household receives some type of public assistance. After Congress enacted welfare reform, it substantially expanded the State Children's Health Insurance Program (SCHIP), which covers children who lack health insurance but whose family income is too high to make them eligible for Medicaid. Because the CPS information on whether a household receives Medicaid assistance includes information on whether the household participates in the SCHIP program, many of the trends in Medicaid participation revealed by the CPS could reflect the creation and rapid growth of the SCHIP program after welfare reform.

In fact, as the bottom panel of figure 3 shows, the trends in program participation rates across the various types of households are quite different when the definition of program participation focuses only on whether the household receives cash or SNAP benefits. At the beginning of the period, both groups of immigrant children had higher participation rates than either native or mixed-parentage 
Figure 5. Differences in Program Participation by National Origin of Immigrant Children, 1994-2009
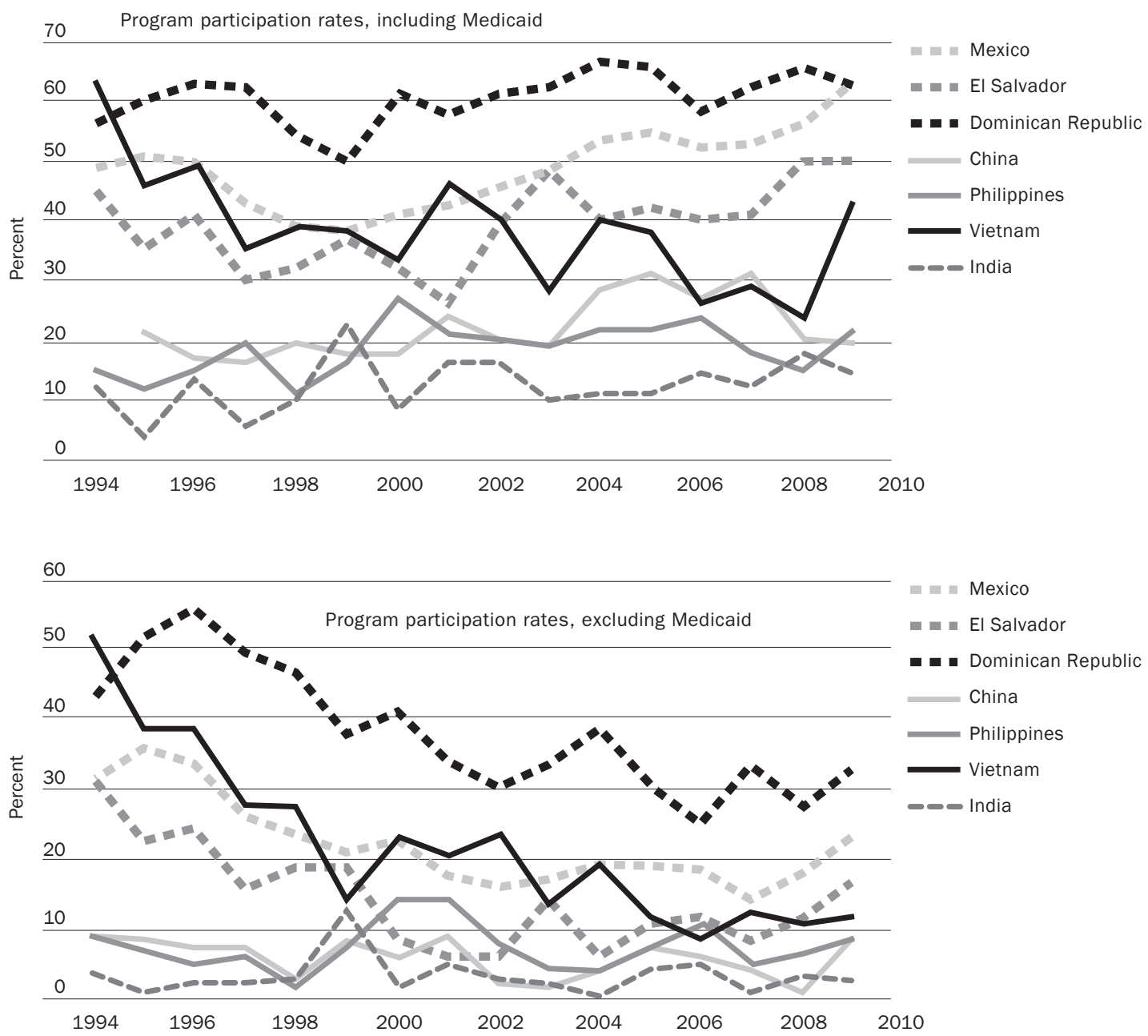

Source: Author's calculations from the 1994-2009 March Current Population Surveys.

Note: The population of immigrant children includes all persons aged seventeen or less whose parents were born outside the United States or its possessions.

children. The enactment of PRWORA led to a very rapid decline in the participation rate of children with two immigrant parents, particularly that of foreign-born children. By the end of the period, foreign-born children have the lowest rate of program participation among the four groups examined, while the participation rate of U.S.-born children with immigrant parents is essentially the same as that of native and mixed-parentage children (though rising very rapidly).
The immigration literature has documented substantial differences in a wide array of socioeconomic outcomes across the various national origin groups that compose the entire immigrant population; these outcomes include educational attainment, wages, labor supply, and participation in public assistance programs. Not surprisingly, poverty rates and program participation rates also differ substantially by national origin groups among children with two immigrant parents. ${ }^{13}$ 
Because the sample size for many national origin groups is so small when foreign-born children are examined separately from those born in the United States, the analysis pools together all children with two immigrant parents into a single group. The national origin of the foreign-born children is, of course, determined by the child's birthplace. That of the U.S.-born children is determined by parental birthplace as follows. About 90 percent of these children are being raised in households where the birthplace of the father and mother are the same. For the remaining 10 percent of the children, the immigrant mother's birthplace determines the national origin of the child. ${ }^{14}$

As figure 4 illustrates, some of the differences in the poverty rates among some of the largest national origin groups in the data are remarkably large. In 2009, only about 6 or 7 percent of the immigrant children from India or the Philippines lived in households that were below the poverty level, compared with nearly 40 percent of children in households from Mexico or the Dominican Republic.

Figure 5 shows that, as with poverty rates, the disparity across national origin groups in the two alternative measures of program participation rates (including and excluding Medicaid) is also large. For example, in 2009, the participation rate (including Medicaid) of immigrant children from India was about 14.6 percent. In contrast, 21.5 percent of children in Filipino households and more than 60 percent of children from Mexico and the Dominican Republic received assistance. The disparity among national origin groups is equally large in the bottom panel of the figure, which excludes Medicaid from the definition of public assistance. In 2009, 2.5 percent of children from India, 11.5 percent of children from Vietnam, 23.2 percent of children from Mexico, and 32.6 percent of children from the Dominican Republic received either cash or SNAP benefits. ${ }^{15}$

The national origin groups with the largest measured poverty and program participation rates also tend to be the largest immigrant groups. In 2009, for example, 46.9 percent of all children with two immigrant parents were of Mexican origin. To the extent that poverty status and program participation among these children are indicators of a young population at risk, figures 4 and 5 suggest the potential for the creation of a large population of disadvantaged persons as these children grow into adulthood. In fact, as I show below, the data indicate the presence of persistent ethnic differences in program participation and poverty status as the children of immigrants transition into young adulthood.

\section{Aging and Cohort Influences on Poverty and Participation Rates}

Research on immigrant economic performance has provided two insights that now serve as "stylized facts" in the immigration debate. First, the typical immigrant worker in the United States suffers a sizable earnings disadvantage (relative to native-born workers) upon arrival, but some of this disadvantage disappears with time spent in the United States (an assimilation, or “aging," effect). Second, skills differ across immigrant cohorts, with more recent cohorts being relatively less skilled than earlier cohorts (a "cohort effect"). The question is whether aging and cohort effects serve to attenuate or exacerbate the differences in poverty rates in the sample of children of immigrants.

The top panel of table 1 "tracks" specific age cohorts of U.S.-born children of immigrants across CPS cross-sections to determine how the poverty rate changes for different 
Table 1. Percentage Point Difference in Poverty Rates between Immigrant and Native Children by Place and Year of Birth

\begin{tabular}{|c|c|c|c|}
\hline \multirow[b]{2}{*}{ Place and year of birth } & \multicolumn{3}{|c|}{ Year of survey } \\
\hline & 1998-99 & 2003-04 & 2008-09 \\
\hline \multicolumn{4}{|c|}{ Immigrant children, U.S.-born } \\
\hline 1994-97 & 11.3 & 8.7 & 8.8 \\
\hline 1999-2002 & $\ldots$ & 8.5 & 10.2 \\
\hline 2004-07 & $\ldots$ & $\ldots$ & 9.8 \\
\hline \multicolumn{4}{|c|}{ Immigrant children, foreign-born } \\
\hline 1994-97 & 12.1 & 15.5 & 15.2 \\
\hline 1999-2002 & $\ldots$ & 6.3 & 13.1 \\
\hline $2004-07$ & $\ldots$ & $\ldots$ & 10.4 \\
\hline
\end{tabular}

Source: Author's calculations from the 1994-2009 March Current Population Surveys.

Note: The population of children includes all persons aged seventeen or less. Immigrant children are those whose parents were born outside the United States or its possessions.

age cohorts. (The birth cohorts and CPS cross-sections are aggregated over a few years of data to increase the number of observations in the sample of specific birth cohorts. The cross-sections do not necessarily follow the same children from period to period.) Consider, for instance, the immigrant children born in the United States in 1994-97. When they were first observed in the 1998-99 pooled cross-section, their poverty rate was 11.3 percentage points higher than that of native children the same age (that is, native children also born in 1994-97). By 2003-04, the children were around nine years old, and the pooled CPS cross-section for this age group reveals that the poverty rate gap between the U.S.born immigrant and native cohorts had narrowed to 8.7 percentage points. By 2008-09, when the children were around fourteen years old, the cross-section showed that the gap in poverty rates between immigrant and native children remained essentially unchanged at 8.8 percentage points. In short, the evidence indicates that the gap in poverty rates between immigrant children born in the United States and native children narrowed over time. In other words, some immigrant children lived in households that moved out of poverty.

In contrast, the bottom panel of the table suggests that the poverty rate of foreignborn immigrant children (relative to native children the same age) grew over the same time period. Consider again the sample of immigrant children born in 1994-97. When this age group was observed in the 1998-99 pooled cross-section, the poverty rate of foreign-born immigrant children was 12.1 percentage points higher than that of comparably aged native children. By 2003-04, that gap had widened to 15.5 percentage points, where it roughly remained for the rest of the period. In short, the data suggest that length of time in the country, at least in terms of its influence on the household's poverty rate, was not an effective mechanism for reducing the disadvantage of foreign-born immigrant children over the past two decades. ${ }^{16}$

\section{Welfare Reform and Poverty}

The data summarized in the previous section suggest different trends in public assistance program participation rates between immigrant children and other groups of children 
Table 2. Difference in Poverty and Program Participation Rates between Immigrant and Native Children in States with Generous and Less Generous Welfare Benefits by Place of Birth and Type of Immigrant Family

\begin{tabular}{|c|c|c|}
\hline \multirow[b]{2}{*}{ Measure, place of birth, type of immigrant family } & \multicolumn{2}{|c|}{ Period } \\
\hline & 1997-2000 & 2001-09 \\
\hline \multicolumn{3}{|l|}{ Immigrant children, U.S.-born } \\
\hline Poverty rate & -1.0 & -3.5 \\
\hline Program participation rate, including Medicaid & 4.4 & 2.8 \\
\hline Program participation rate, excluding Medicaid & 2.7 & 0.2 \\
\hline \multicolumn{3}{|l|}{ Immigrant children, foreign-born } \\
\hline Poverty rate & -1.4 & -3.7 \\
\hline Program participation rate, including Medicaid & 1.3 & 7.0 \\
\hline Program participation rate, excluding Medicaid & -0.8 & -1.0 \\
\hline \multicolumn{3}{|l|}{ Children of mixed parentage } \\
\hline Poverty rate & 1.7 & 2.5 \\
\hline Program participation rate, including Medicaid & -0.9 & -0.2 \\
\hline Program participation rate, excluding Medicaid & 1.2 & 0.7 \\
\hline \multicolumn{3}{|c|}{$\begin{array}{l}\text { Source: Author's calculations from the } 1994-2009 \text { March Current Population Surveys. } \\
\text { Note: Cell entries are percentage points. Program participation rates indicate whether the child lives in a household that receives } \\
\text { either cash or SNAP benefits and either includes or excludes Medicaid. Table entries are percentage point differences between immi- } \\
\text { grant and native children. }\end{array}$} \\
\hline
\end{tabular}

immediately after 1996. In particular, program participation of immigrant children, particularly of those born abroad, declined at a faster rate in the last half of the 1990s.

These differential trends between immigrants and natives are typically attributed to the enactment in 1996 of PRWORA, which set newly restrictive rules for determining the eligibility of foreign-born persons for practically all types of public assistance. In rough terms, PRWORA denies most types of federal means-tested assistance (such as TANF and Medicaid) to noncitizens who arrived after the legislation was signed and limits the eligibility of many noncitizens already living in the United States.

The legislation, however, gave states the option to offer TANF and Medicaid to some of these immigrants through state-funded programs, and some states opted to do so in the years immediately after the law was enacted. These state choices, designed to offset the federal cutbacks, obviously increase the degree of dispersion in "welfare opportunities" available to immigrants living in different states.

The Urban Institute has constructed an index of "welfare generosity" that classifies states into four categories according to the availability of the state-funded safety net. ${ }^{17}$ The states where such aid was "most available" included California and Illinois; the states where the aid was "somewhat available" included New York and Florida; the states where the aid was "less available" included Arizona and Michigan; and the states were the aid was "least available" included Ohio and Texas. Many of the states that chose to offer above-average levels of state-funded assistance to immigrants in the aftermath of the PRWORA cutbacks were those with the largest immigrant populations.

Table 2 summarizes the results of a regression analysis designed to determine whether 
the poverty rates and program participation rates of immigrant children who lived in a generous state (defined as a state where the state-funded assistance was either "most available" or "somewhat available") differed from those of the immigrant children who lived in the less generous states. By design, the impacts summarized in the table are relative to the changes observed among native children, so that they net out any statespecific factors that might affect the pre- and post-1996 trends. ${ }^{18}$ Note that the table also reports the impact of PRWORA both in the short run (immediately after enactment, in 1997-2000) and in the long run (2001-09).

The data reveal that the state-level provisions of PRWORA significantly increased the fraction of immigrant children who receive public assistance in the more generous states, both in the short and in the long run. This increase, however, is evident only when the measure of program participation includes Medicaid. Hence it seems that states were able to attenuate the impact of the federal cutbacks through the provision of health services (either through the Medicaid program itself or the expansion of SCHIP to immigrant children). The impact of living in a "generous" state is numerically important. In particular, residing in a generous state permanently increased the program participation rate of U.S.-born immigrant children by about 2.8 percentage points and that of foreign-born immigrant children by about 7.0 percentage points above the rates for the two groups of immigrant children residing in the less generous states-even after netting out any state differences that would be reflected in the program participation rate of native children. The results are quite different for children of mixed parentage, however; the state-level provisions of PRWORA had no such impact on their program eligibility, and thus their participation rate did not change significantly.

Table 2 also summarizes the impact of the state-funding provisions in PRWORA on the poverty rate of the various groups of children. The evidence is striking. By providing additional assistance to immigrant children, especially through the Medicaid-SCHIP programs, the generous states were able to reduce the poverty rate of immigrant children, regardless of where they were born, by about 3.5 percentage points in the long run. It is unclear why the additional assistance provided through the Medicaid-SCHIP program reduced poverty rates, particularly since participation in these programs does not enter the calculation of the poverty threshold. Nevertheless, the additional resources provided to immigrant children are correlated with a significant improvement in the economic status of the immigrant families.

\section{Source of Differences}

The previous sections documented substantial differences between children with two immigrant parents and other groups of children in poverty and program participation rates. I now examine the extent to which differences in socioeconomic and human capital characteristics explain some of this dispersion.

By one major indicator, immigrant children appear to have an advantage over native children. The presence or absence of parents in the household is well known to be perhaps the most important determinant of children's program participation and poverty status. ${ }^{19}$ The economic well-being of children is typically better in two-parent households, and immigrant children, regardless of where they were born, are far more likely to live in two-parent households than other children. If anything, the immigrant advantage 
Table 3. Percentage Points by which Poverty and Program Participation Rates among Immigrant Children Exceed Those among Native Children by Place of Birth and Type of Immigrant Family

\begin{tabular}{|c|c|c|c|}
\hline \multirow[b]{2}{*}{ Measure, place of birth, type of immigrant family } & \multicolumn{3}{|c|}{ Specification } \\
\hline & 1 & 2 & 3 \\
\hline \multicolumn{4}{|l|}{ Poverty rate } \\
\hline Mixed-parent children & -0.1 & 1.4 & 0.4 \\
\hline Immigrant children, U.S.-born & 10.3 & 11.6 & 4.5 \\
\hline Immigrant children, foreign-born & 15.4 & 16.9 & 10.3 \\
\hline \multicolumn{4}{|l|}{ Program participation rate, including Medicaid } \\
\hline Mixed-parent children & 0.5 & 2.2 & 1.5 \\
\hline Immigrant children, U.S.-born & 13.1 & 14.2 & 6.9 \\
\hline Immigrant children, foreign-born & 7.1 & 8.7 & 2.4 \\
\hline \multicolumn{4}{|l|}{ Program participation rate, excluding Medicaid } \\
\hline Mixed-parent children & -1.1 & 0.4 & -0.3 \\
\hline Immigrant children, U.S.-born & 1.8 & 3.1 & -2.4 \\
\hline Immigrant children, foreign-born & -0.9 & 0.6 & -4.3 \\
\hline \multicolumn{4}{|l|}{ Adjusts for } \\
\hline Year of observation & Yes & Yes & Yes \\
\hline $\begin{array}{l}\text { Two-parent household, number of children, } \\
\text { number of elderly persons, head's age, } \\
\text { state of residence }\end{array}$ & No & Yes & Yes \\
\hline Head's educational attainment & No & No & Yes \\
\hline
\end{tabular}

Source: Author's calculations from the 1994-2009 March Current Population Surveys.

Notes: The measure of the program participation rate indicates whether the child lives in a household that receives either cash or SNAP benefits. Columns further to the right include more controls for household characteristics. The last column represents the best estimate of the effect of immigrant status alone.

has increased over time. By 2009 , nearly 65 percent of native children and 69 percent of mixed-parent children lived in two-parent households, while about 75 percent of children with two immigrant parents lived in two-parent households.

The evidence, instead, points to a very different source for the higher rates of poverty and program participation observed among immigrant children relative to native children. Table 3 reports the difference in poverty rates and program participation between children with one or two immigrant parents and native children, after adjusting for a host of socioeconomic background characteristics. The first column of the table, reports the raw differences among the groups after adjusting for period effects. For example, the typical foreign-born child with two immigrant parents has a poverty rate that is about 15.4 percentage points higher than that of native children, while the typical U.S.-born child of two immigrant parents has a poverty rate that is 10.3 percentage points higher than that of a native child.

The second column of the table reports the adjusted differential after controlling for differences in such characteristics as state of residence, household composition, and the age of the head of the household. If anything, adjusting for these differences increases the relative disadvantage of immigrant children. The poverty rate gap rises from 15.4 to 16.9 percentage points for the foreign-born children and from 10.3 to 11.6 percentage points for the U.S.-born children. 
Finally, the third column presents the adjusted differential after controlling for differences in the educational attainment of the head of the household. Not surprisingly, this variable plays a crucial role in generating differences among the various types of children. In fact, it cuts by at least one-third to onehalf the difference in poverty rates between immigrant children and native children. The remaining rows of the table show that the adjusted gap in participation rates, regardless of whether Medicaid is included, falls to near zero after adjusting for differences in educational attainment among parents. In short, the evidence clearly suggests that human capital differences in the households of immigrant and native children account for a large portion of the observed disadvantage experienced by immigrant children.

\section{Does the Immigrant Disadvantage Persist into Young Adulthood?}

The long-run importance of exposure to poverty and program participation during childhood depends on the extent to which that exposure affects outcomes of the children after they grow up and leave school. The available CPS data do not permit a direct analysis, because no longitudinal sample of a sufficiently large group of immigrant children exists that would allow the tracking of specific individuals over time and hence the precise measurement of such consequences.

As I showed earlier, however, program participation and poverty rates vary a great deal among national origin groups in the population of immigrant children. The immigration literature has often exploited these national origin differences to measure the extent of social mobility across generations..$^{20}$ The CPS data can be used in a similar fashion to determine if some of the national origin differences observed among immigrant children persist a decade or two later in young adulthood.

In particular, the 1994-96 pooled CPS data can be used to calculate the poverty rate of children aged five to fifteen with two immigrant parents for each of a number of national origin groups. ${ }^{21}$ Moving forward thirteen years, the 2007-09 pooled CPS can then be used to calculate the poverty rate for a cross-section of persons aged eighteen to twenty-eight, with two immigrant parents, in the same national origin groups. The top panel of figure 6 illustrates the nature of the correlation between the poverty rates experienced by children of different national origins and the poverty rates experienced by young adults of the same national origin groups thirteen years later.

The horizontal axis of the scatter diagram gives the poverty rates of immigrant children (aged five to fifteen) by national origin group in 1994-96, and the vertical axis gives the poverty rates thirteen years later for young immigrant adults aged eighteen to twentyeight, the age range the immigrant children would now be. The data show a positive correlation: The national origin groups with children with the highest poverty rates become the groups with young adults with the highest poverty rates.

The upward-sloping regression line illustrated in figure 6 summarizes the statistical correlation that links the poverty rates of the young adults to their experience when they were children. The slope of this regression line measures the degree of persistence in the particular outcome over time as children exit childhood and become young adults. A relatively flat regression line would indicate little connection between the economic outcomes experienced at the time of childhood 
Figure 6. Outcomes in Childhood and Young Adulthood for Immigrant Children, by Country of Origin
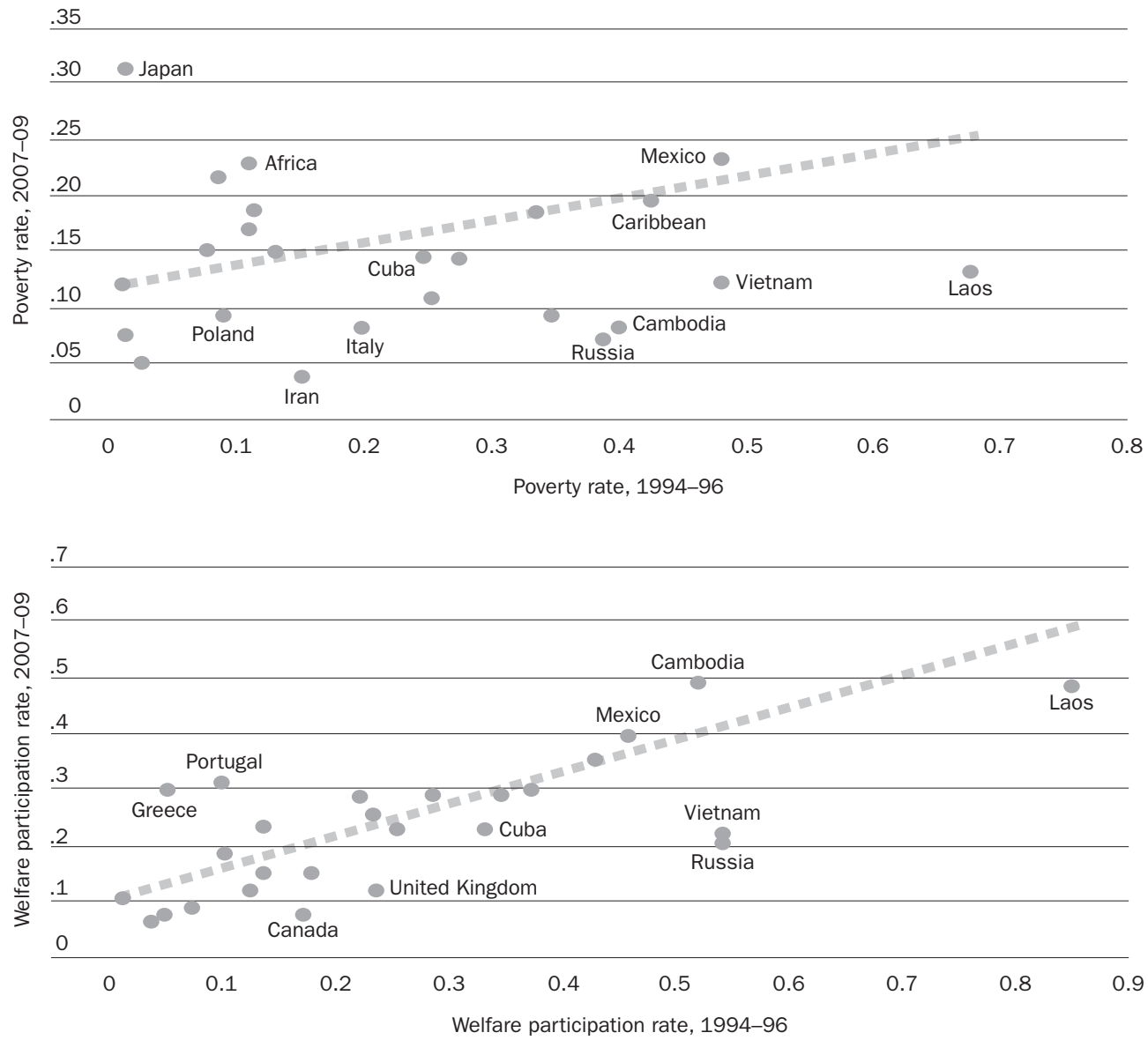

Source: Author's calculations from the 1994-2009 March Current Population Surveys.

Note: The figure provides information for twenty-four national origin groups. Each group satisfies the restriction that there were at least thirty observations in both the 1994-96 and 2007-09 pooled CPS cross-sections for the particular ethnic group. The population of immigrant children includes all persons aged seventeen or less whose parents were born outside the United States or its possessions. The program participation rates used in the bottom panel of the figure include participation in the Medicaid program. See text for explanation.

and as young adults. Put differently, all young adults would have relatively similar poverty rates regardless of the differences at the time they were children. A relatively steep regression line suggests a substantial link between poverty rates over time. In fact, the slope of the regression line in the top panel of figure 6 is 0.205 (with a standard error of 0.058). ${ }^{22}$ In other words, about a fifth of the poverty gap between immigrant children in any two national origin groups in the figure persists as immigrant children become young adults and set up their own households. There is, therefore, some persistence in poverty rates in immigrant households. Note, moreover, that the vast majority of these children were born in the United States, so even among U.S.-born adults, ethnicity matters quite a bit.

The bottom panel of figure 6 illustrates a similar scatter diagram for program participation 
rates (including Medicaid). Again, the correlation is noticeably positive between the participation status of the household where the children grew up and the participation status of the households of young adults thirteen years later. The slope of the regression line is 0.571 (with a standard error of 0.082), so participation status also tends to persist over time, and the link is even stronger than that observed in poverty rates.

The correlations illustrated in figure 6 can be interpreted in two distinct ways. It is likely, for instance, that specific individuals or groups may experience a great deal of long-term persistence in outcomes over time. In other words, a set of permanent factors may be associated with specific individuals or groups that tend to lead to "good" or "bad" outcomes systematically over time. ${ }^{23}$ Alternatively, exposure to adverse socioeconomic outcomes in childhood (such as poverty or welfare dependency) may increase the likelihood of adverse economic outcomes in young adulthood. Although a disentangling of these two explanations would greatly increase the understanding of how childhood environmental factors affect the coming of age of immigrant children, the relative importance of the two factors cannot easily be isolated in the data.

\section{Conclusions}

Whether they are foreign-born or U.S.born, children with two immigrant parents form the fastest-growing component of the population of persons under age eighteen in the United States. They are also much more likely to be exposed to poverty and public assistance than other children. In fact, the exposure rates are remarkably high. Nearly half of these children live in households that receive some type of public assistance, and about one-third live in poverty. Much of the relatively larger disadvantage experienced by immigrant children can be traced back to the relatively lower educational attainment of the parents in immigrant families. Moreover, these social and economic disadvantages persist into young adulthood. For instance, the national origin groups where immigrant children had the largest poverty and program participation rates are also the national origin groups where young adults (more than a decade later) also have the largest poverty and program participation rates.

The implications of these basic facts have not yet been examined, although they are sure to generate much future discussion regardless of how one perceives the costs and benefits of alternative social policies designed to address the problem. However, future research will need to determine the causal impact of childhood poverty on immigrant adult outcomes and delineate the reasons why this causal impact might differ between immigrant and native families. Successful policies for addressing the potential problems caused by the intergenerational breeding of poverty and program participation in the immigrant population can be developed only after the causal mechanism is well understood. Therefore, the study of the social and economic consequences of exposure to poverty and program participation in the fastestgrowing segment of children in the U.S. population will inevitably receive a great deal of attention in the coming decades. 


\section{Endnotes}

1. Barry Edmonston and Jeffrey S. Passel, "Immigration and Immigrant Generations in Population Projections," International Journal of Forecasting 8, no. 3 (1992): 459-76.

2. Classic expositions of the melting-pot hypothesis are given by Robert Park, Race and Culture (Glencoe, Ill.: Free Press, 1975); and Milton Gordon, Assimilation and American Life (Oxford University Press, 1964). Recent empirical studies include George J. Borjas, "Long-Run Convergence of Ethnic Skill Differentials: The Children and Grandchildren of the Great Migration," Industrial and Labor Relations Review 47, no. 4 (1993): 553-73; Richard D. Alba, Amy Lutz, and Elena Vesselinov, "How Enduring Were the Inequalities among European Immigrant Groups in the U.S.?” Demography 38, no. 3 (2001): 349-56; and Alejandro Portes and Min Zhou, "The New Second Generation: Segmented Assimilation and Its Variants," Annals of the American Academy of Political and Social Science 530 (1993): 74-96. Some of the conflicting evidence is surveyed by Min Zhou, "Segmented Assimilation: Issues, Controversies, and Recent Research on the New Second Generation," International Migration Review 31, no. 4 (1997): $825-58$.

3. There are a number of excellent reviews of this literature. See, in particular, Jeanne Brooks-Gunn and Greg J. Duncan, "The Effects of Poverty on Children," Future of Children 7, no. 2 (1997): 55-71; Greg J. Duncan and others, "How Much Does Childhood Poverty Affect the Life Chances of Children?" American Sociological Review 63, no. 3 (1998): 406-23; and Robert Haveman and Barbara Wolfe, "The Determinants of Children's Attainments: A Review of Methods and Findings," Journal of Economic Literature 32, no. 4 (1995): 1829-78. A particularly useful overview of recent trends and implications for policy is given by Kristin Anderson Moore and others, "Children in Poverty: Trends, Consequences, and Policy Options,” policy brief, Child Trends 2009-11 (Clearwater, Fla.: JWB Children’s Services Council of Pinellas County, Florida, April 2009) (www.aboutpinellaskids.org/childpoverty/Child\%20Poverty\%20 Brief.pdf).

4. Greg J. Duncan, and Jeanne Brooks-Gunn, "Income Effects across the Life Span: Integration and Interpretation," in Consequences of Growing Up Poor, edited by Greg J. Duncan and Jeanne BrooksGunn (New York: Russell Sage Foundation, 1997), pp. 596-610. There is a debate about whether it is poverty itself or other variables correlated with poverty (such as not having enough books in the household or inferior child care) that generates the correlation between poverty and a host of poor socioeconomic outcomes. See, for example, Susan B. Meyer, What Money Can't Buy: Family Income and Children's Life Chances (Harvard University Press, 1997).

5. See, for example, Lorraine V. Klerman, "The Health of Poor Children: Problems and Programs," in Children and Poverty: Child Development and Public Policy, edited by A. Huston (Cambridge University Press, 1991), pp. 136-57; and Sanders Korenman and Jane E. Miller, "Effects of Long-Term Poverty on Physical Health of Children in the National Longitudinal Survey of Youth," in Consequences of Growing Up Poor, edited by Duncan and Brooks-Gunn, pp. 70-99 (see note 4). A study that specifically examines whether the poverty status of immigrant children influences mental health, although in the Canadian context, is Morton Beiser and others, "Poverty, Family Process, and the Mental Health of Immigrant Children in Canada," American Journal of Public Health 92, no. 2 (2002): 220-27.

6. Mary E. Corcoran, and Ajay Chaudry, "The Dynamics of Childhood Poverty," Future of Children 7, no. 2 (1997): 40-54; Thomas P. Vartanian, “Adolescent Neighborhood Effects on Labor Market and 
Economic Outcomes," Social Service Review 73, no. 2 (1999): 142-67; and Robert M. Hauser and Megan M. Sweeney, "Does Poverty in Adolescence Affect the Life Chances of High School Graduates?" in Consequences of Growing Up Poor, edited by Duncan and Brooks-Gunn, pp. 541-95 (see note 4).

7. A very small fraction of children with mixed parents were born outside the United States (3.3 percent in 2009). Because of the small sample size, the birthplace distinction within the population of mixed-parent children is ignored in the discussion that follows.

8. In addition to the age restriction, a "child" cannot be a household head or the spouse of a household head.

9. There is remarkably little intermarriage across national origin groups among parents of immigrant children: only about 10 percent of immigrant children have parents belonging to different national origin groups, and this fraction was very stable during the period. Specifically, the intermarriage rate among the parents of immigrant children was 10.5 in 1994 and 10.3 percent in 2009.

10. The income used to calculate the household's poverty status includes cash assistance but does not include the value of food stamps or Medicaid.

11. Evidence on the beneficial outcomes resulting from the expansion of Medicaid coverage of children is given by Janet Currie and Jonathan Gruber, "Health Insurance Eligibility, Utilization of Medical Care, and Child Health," Quarterly Journal of Economics 111, no. 2 (1996): 431-66.

12. See George J. Borjas, "Welfare Reform and Immigration," in The New World of Welfare: An Agenda for Reauthorization and Beyond, edited by Rebecca Blank and Ron Haskins (Washington: Brookings Institution Press, 2001), pp. 369-85; and Michael Fix and Jeffrey S. Passel, Trends in Noncitizens' and Citizens' Use of Public Benefits following Welfare Reform: 1994-97 (Washington: Urban Institute, 1999).

13. Some differences in outcomes appear among mixed-parent children (assuming that the child is assigned to the ethnic group of the foreign-born parent), but these differences are much smaller than the ones observed existing among immigrant children.

14. Because the proportion of mixed-birthplace children is small, the results are not sensitive either to the alternative methodology of allocating national origin according to the birthplace of the father or to the simple elimination of these children from the analysis.

15. Eligibility rules for refugees differ dramatically from the rules that apply to other immigrants and could influence program participation rates for children from countries, such as Vietnam, with high numbers of refugees. In particular, the eligibility of refugees for public assistance is not affected by the citizenship status of the child or the parents. The different eligibility rules for refugees and nonrefugees are sure to play a much greater role in the post-PRWORA period.

16. The data reported in table 1 can also be used to determine the presence of "cohort effects," where the cohorts refer to different year-of-birth cohorts. (Note that this definition of cohorts differs from that traditionally used in the immigration literature, which defines immigrant cohorts by calendar year of migration rather than by calendar year of birth.) The evidence on the direction of these cohort effects is mixed, however. For example, the poverty rate is about 12.1 percentage points higher for immigrant children born abroad in 1994-97 than for comparably aged natives in 1998-99, when the children are around four years old. In contrast, the relative poverty rate for immigrant children born in 1999-2002 is 6.3 percent when they are four years old; for the cohort born in 2004-07 it is 10.4 percent when they are four years old. 
17. Wendy Zimmermann and Karen C. Tumlin, "Patchwork Policies: State Assistance for Immigrants under Welfare Reform,” Occasional Paper 24 (Washington: Urban Institute, 1999), table 18; and Karen C. Tumlin, Wendy Zimmermann, and Jason Ost, "State Snapshots of Public Benefits for Immigrants: A Supplemental Report to 'Patchwork Policies,"” Occasional Paper 24 supplemental report (Washington: Urban Institute, 1999).

18. In particular, the regression analysis relates the dependent variable to a set of linear fixed effects, including the time period under analysis, whether the child is a child of mixed-parentage or an immigrant child, and whether the state is a generous state. The regression analysis then includes all two-way interactions among these variables, and a three-way interaction between the immigration status of the child, the state generosity index, and the time period. The effects reported in table 2 give the estimated coefficient of the three-way interaction variable.

19. Excellent discussions of the consequences of growing up in single-parent households are given by Kathryn Edin and Laura Lein, Making Ends Meet: How Single Mothers Survive Welfare and Low-Wage Work (New York: Russell Sage Foundation, 1997); and Sara McLanahan and Gary D. Sandefur, Growing Up with a Single Parent: What Hurts, What Helps (Harvard University Press, 1994).

20. George J. Borjas, “The Intergenerational Mobility of Immigrants," Journal of Labor Economics 11, no. 1, part 1 (1993): 113-35.

21. The pooling of three different CPS cross-sections generates a larger sample size for each of the ethnic groups, allowing for a more precise measurement of the underlying correlation. In addition, the ethnic groups are defined by collapsing the five-digit coding provided by the original data into a three-digit coding. Further, all immigrant children, regardless of where they were born, are pooled into the same ethnic groups using the methodology outlined here.

22. The regression line weights each ethnic group by the number of observations used to calculate the mean outcome for the group in the pooled 2007-09 CPS data.

23. The correlation between the program participation rate of immigrant children and the participation rate observed thirteen years later when they become young adults persists even after one adjusts for differences in educational attainment across groups. The regression coefficient linking the welfare participation rate over time is 0.358 (with a standard error of 0.090) if the model adjusts for differences in the educational attainment of the ethnic groups (with the educational attainment measured as of 2007-09). It seems, therefore, as if exposure to public assistance programs during the childhood years has an independent effect on the program participation rate of young adults even after one adjusts for the intergenerational human capital transfers that inevitably take place. Note, however, that the educational attainment of the group is an imperfect measure of the human capital of the group, and hence this type of model cannot be used to differentiate conclusively between the two alternative hypotheses that can explain the persistence of the outcomes illustrated in figure 6. 

